to ruminate on the costs of not having a sustainable business plan.

The Lorax leaves in despair, and the Once-ler hands over the task of restoring the Truffula ecosystem by giving the world's last Truffula seed to a child.

The Lorax himself is a parody of a misanthropic ecologist: "He was shortish. And oldish. And brownish. And mossy. And he spoke with a voice that was sharpish and bossy." He hectors and pleads, he "speaks for the trees", but the Once-ler pays no attention until it is too late, saying, "All you do is yap-yap and say, 'Bad! Bad! Bad! Bad!'” That approach seems a little dated in this era of 'win-win' solutions. But Seuss understood, even back then, the limits of gloom and doom. The Lorax fails. Nevertheless, Seuss clearly had great affection for his impassioned little nag, as do the book's legions of fans.

Perhaps the source of its enduring appeal has less to do with Seuss's prescience about the futility of ecological doomsaying than with environmentalists' nostalgia for a time when such problems seemed more black and white. The Lorax portrays a world without the complexities of carbon trading, the pricing of ecosystem services, uncertainties over baseline states and the existence or not of pristine wilderness. For Seuss, wild nature is a paradise, industry is a malignant cancer and heroes take a stand.

Then again, that old narrative has not been entirely displaced by the bureaucrats who set green targets at international meetings. Diverse natural land is threatened by industries; smog chokes skies; Gluppity-Glupp fouls waterways; people use natural resources like there is no tomorrow. We still need heroes to speak for the trees.

Will I read my daughter The Lorax when she graduates from Pat the Bunny? I'm not sure. It captures the basics of why mismanagement and overexploitation of ecosystems are a bad idea in a way that children can understand. And because I believe that her generation's challenge will be to manage the planet consciously, perhaps it is not too early to teach those lessons. But this is a gloomy book. The final image - of the Truffula seed hurtling into a tiny pair of hands - puts a lot of responsibility on small shoulders. Perhaps it is more important for her to learn the pleasures and beauty of nature first. Afternoons spent poking in the mud, catching cicadas and mapping out squirrel routes may be more likely to turn her green than the spectre of a world without Truffula trees.

Emma Marris writes for Nature from Columbia, Missouri.

\title{
How Earth shaped up
}

Andrew Robinson enjoys an account of the first
expedition to the equator to calibrate latitude.

$\mathrm{W}$

hat was the world's first international scientific expedition? Scientist-explorers of the Enlightenment, such as Alexander von Humboldt, would have answered without hesitation: the French government's eightyear geodesic mission to the Spanish colony of Peru, beginning in 1735. The mission the subject of Measure of the Earth - calculated the precise length of a degree of latitude at the equator, thereby helping to define Earth's shape.

Today, the geodesic mission's fame has faded. Until this book, no modern history of the mission has been published in English (unpublished academic studies exist). It was virtually ignored in Ken Alder's prizewinning account of the surveying of the arc of the meridian and the origins of the metric system, The Measure of All Things (Free Press, 2002). Neil Safier's Measuring the New World (University of Chicago Press, 2008) focused instead on the Amazon explorations of its best-known member, Charles-Marie de La Condamine. But in 2006, the French geodesic mission was the basis for one episode in a BBC television series, Voyages of Discovery, for which the historical consultant was science writer and naval historian Larrie Ferreiro. In Measure of the Earth, Ferreiro puts this important, dramatic and gruelling trip back on the map.
D NATURE.COM measuring the meridian: go.nature.com/xrgrvs
For more on

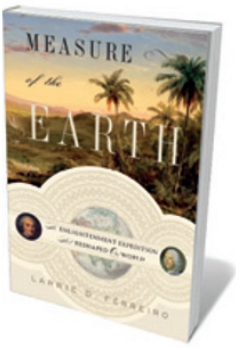

Measure of the Earth: The Enlightenment Expedition That Reshaped Our World LARRIE D. FERREIRO Basic Books: 2011. 376 pp. $\$ 28, £ 15.99$

The geodesic mission was organized by the French Academy of Sciences, under the sponsorship of the French minister of the navy acting in wary collaboration with his Spanish counterpart in Madrid. Spain sent two naval officers, also astronomers, to learn from and keep an eye on the French.

Along with a similar French scientific mission to the Arctic Circle in 1736-37, the expedition determined that a degree of latitude is shorter at the equator (where it measures a length of 56,753 toises, or 110.54 kilometres) than at Paris (57,060 toises) or towards the North Pole (57,437 toises). Thus it proved that Earth was not a sphere but an oblate spheroid: it bulges slightly at the equator and is slightly flattened at the poles.

This asymmetry explains why the force of gravity is slightly less near the equator than in Paris. This was first observed by a puzzled French astronomer measuring the period of a pendulum clock in Guyana in 1672, and seized on by Isaac Newton in his Principia Mathematica of 1687 . Newton predicted the oblate shape of Earth from his theory of

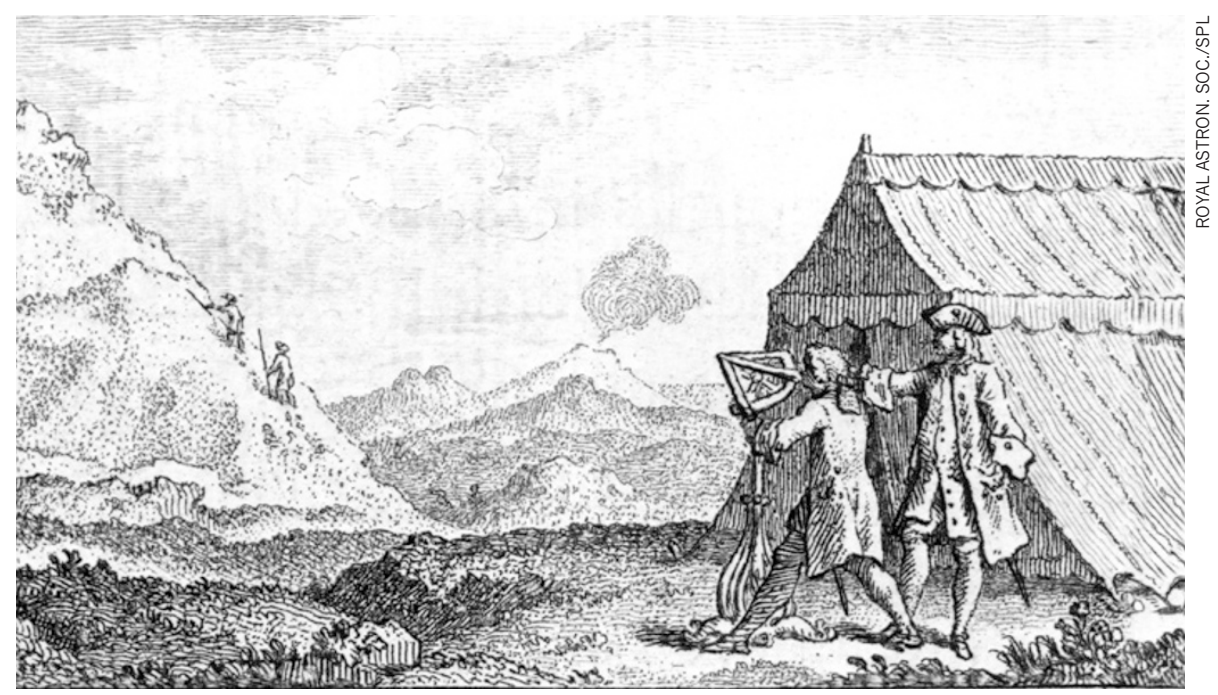

The 1730s French geodesic mission revealed that Earth bulges at the equator. 
gravity. However, his idea was strongly contested in France by followers of philosopher René Descartes, whose theory of vortices in the ether had led them to the view that Earth must be prolate, like an upright egg. The geodesic mission thus settled a long scientific debate, and at the same time improved the accuracy of navigation by ships.

By 1735, the basic geometric and astronomical principles of trigonometric surveying were well understood. To the government and scientists in Paris, it seemed straightforward to apply these accurately among the peaks of the Andes, over a period of a year or two. But the expedition members had reck-

"The expedition
had reckoned
without
obstacles
including
yellow fever,
locall love
affairs and
brigandry."
oned without a myriad of obstacles, large and small, including precarious mountain transport, extreme weather, earthquakes, altitude sickness, yellow fever, local love affairs and brigandry. They suffered the theft of their triangulation signals by local Indians, damage to instruments, the withdrawal of their French funding, Spanish colonial politics and the ripples from European wars, as well as the murder of their surgeon at a bullfight.

There were also purely scientific challenges, such as stellar aberration: the then little-understood phenomenon of tiny variations in the location of the stars used to fix latitude, which we now know arises as a result of Earth's motion around the Sun.

The most serious problem was the expedition's lack of leadership. Internecine squabbling nearly scuppered the project. The precious results announced to the French Academy in 1744 by expedition member and geophysicist Pierre Bouguer were those measured by himself and La Condamine, without the knowledge of the official expedition leader, Louis Godin, who decided to remain in South America as a professor of mathematics in Lima. Measure of the Earth accomplishes its mission with skill and devotion, although it lacks some necessary diagrams. Its intermixing of politics and science is particularly fascinating. It also shows, unintentionally, the astonishing development of international scientific cooperation since the days of the Enlightenment pioneers.

Andrew Robinson is author of The Story of Measurement. e-mail: andrew.robinson33@virgin.net

\section{ANTHROPOLOGY}

\section{Head to head}

\section{A scenario blaming rats for the devastation of Easter Island doesn't account for recent results, argues Paul Bahn.}

$\mathrm{E}$ aster Island, or Rapa Nui, is a perennial favourite of scholars and the media because of its numerous giant stone figures and supposed mysteries. Most of these enigmas - including the origins of the statues and the denuded landscape - have been solved in recent decades through painstaking work by archaeologists, anthropologists, environmentalists, linguists and geneticists.

A consensus view has emerged, summarized in Easter Island, Earth Island (Thames and Hudson; 1992) by botanist John Flenley and myself, that the island was deforested by its inhabitants. They cleared the land for crops and used timber for the transport and erection of ever more statues, with war the end result. In The Statues That Walked, archaeologists Terry Hunt and Carl Lipo present a different picture, portraying the islanders as environmentally sensitive and peace-loving until Europeans arrived in the eighteenth century. But some recent publications don't support their hypothesis.

Since the first known visit to the island by European vessels in 1722, people have wondered how so many huge stone statues could be transported and raised, given the lack of available timber. Discoveries of root moulds, pollen grains and stumps showed that the island was originally covered in millions of large palms and other tree species. Analyses of pollen and plant macrofossils revealed drastic deforestation between the thirteenth and

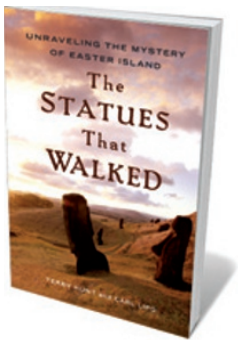

The Statues

That Walked:

Unraveling the

Mystery of Easter Island

TERRY HUNT AND

CARL LIPO

Free Press: 2011.

256 pp. $\$ 26$ seventeenth centuries, long before the Europeans arrived.

A wide range of evidence, along with oral traditions, suggest that the Easter Islanders had lived cooperatively for centuries after their arrival from Polynesia, probably in the early centuries AD. A thousand years later, they were in conflict, living in a barren landscape. The ecological decline of this small island serves as a warning of what is happening to Earth as a whole, as argued by Flenley and myself, and by geographer Jared Diamond in his best-seller Collapse (Viking, 2004).

Inevitably, this scenario has elicited doubts. Archaeologists Catherine and Michel Orliac have speculated that the island's deforestation was largely due to drought or climatic change, which may indeed have played a part. Others, including Hunt and Lipo, contend that the islanders ills were caused by the arrival of Europeans, rather than internal social pressures.

In The Statues That Walked, Hunt and Lipo argue for a late date of around $1200 \mathrm{AD}$ for the

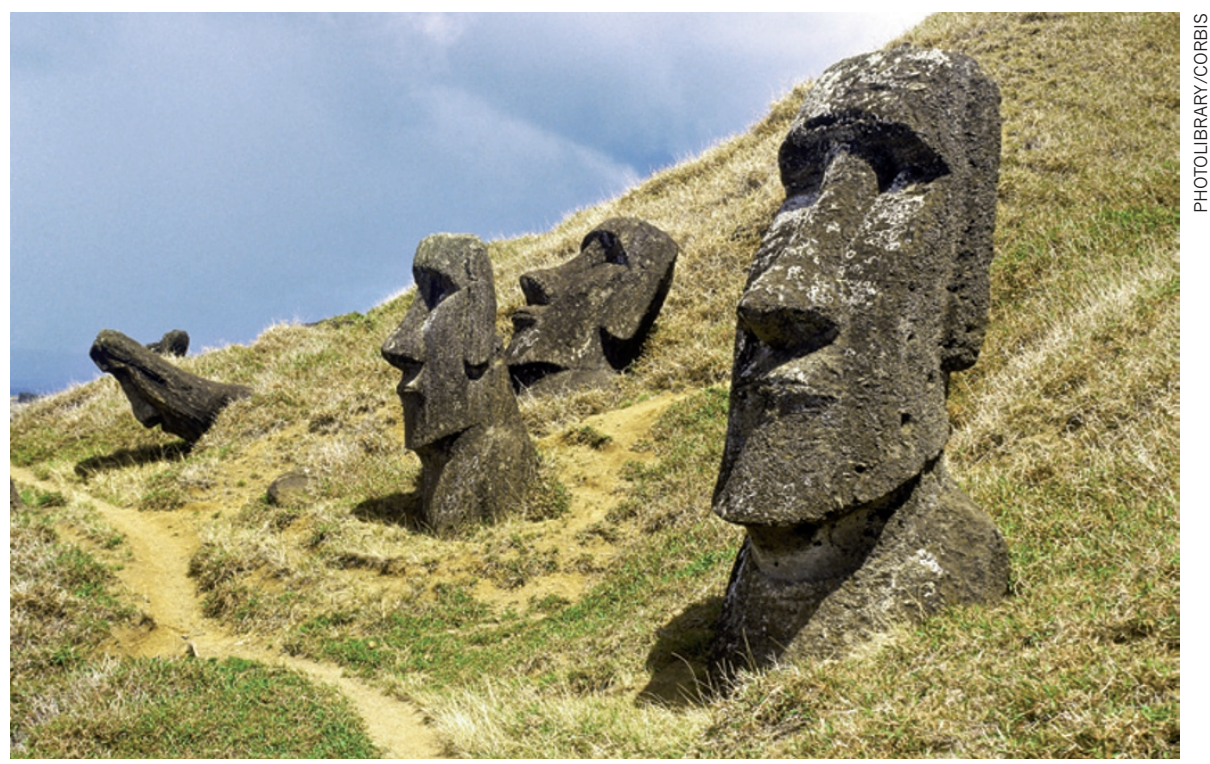

Debate surrounds the transportation of Easter Island's statues and the disappearance of its forests. 